\title{
Adrenal Hormones Suppress Cell Division in the Adult Rat Dentate Gyrus
}

\author{
Elizabeth Gould, Heather A. Cameron, Deborah C. Daniels, Catherine S. Woolley and Bruce S. McEwen \\ Laboratory of Neuroendocrinology, The Rockefeller University, New York, New York 10021
}

\begin{abstract}
The rat dentate gyrus is unusual among mammalian brain regions in that it shows cell birth well into adulthood. During development, dentate gyrus cell birth is regulated by adrenal steroids. However, it is presently unknown whether cell division in the adult is also mediated by these same factors. In order to determine whether this is the case, we combined adrenalectomy, with or without corticosterone (CORT) replacement, and ${ }^{3} \mathrm{H}$-thymidine autoradiography, Nissl staining, and immunohistochemistry for the glial cell markers vimentin and glial fibrillary acidic protein (GFAP) as well as for the neuronal marker neuron-specific enolase. Removal of circulating adrenal steroids resulted in a greater density of both GFAP-immunoreactive and vimentin-immunoreactive cells compared to sham-operated animals; CORT replacement prevented increases in both of these cell types. The increase in the density of vimentin-immunoreactive cells probably resulted from an increase in the birth of these cells, as adrenalectomized rats showed greater numbers of ${ }^{3} \mathrm{H}$ thymidine-labeled vimentin-positive cells compared to sham rats. In contrast, no changes in the number of ${ }^{3} \mathrm{H}$-thymidinelabeled GFAP-positive cells were observed with adrenalectomy, indicating that the increase in this cell type probably does not involve cell birth. In addition, the density of ${ }^{3} \mathrm{H}$ thymidine-labeled cells that were not immunoreactive for either glial cell marker and that showed neuronal characteristics was dramatically increased with adrenalectomy. These results suggest that adrenal hormones normally suppress the birth of both glia and neurons in the adult rat dentate gyrus.
\end{abstract}

The dentate gyrus is unique in the mammalian brain in that it shows many processes, such as cell birth, death, and migration, into adulthood that are typically observed in other brain regions only during discrete developmental periods. Several studies have shown that the adult rat dentate gyrus continues to produce a small but steady number of both neurons and glia up until at least a year (Kaplan and Hinds, 1977; Kaplan and Bell, 1984). The presence of a low but predictable number of pyknotic cells in the granule cell layer (Gould et al., 1990a) suggests that cell death is an ongoing process in adults as well. Migration has also been demonstrated to occur in the adult rat dentate gyrus; newly

\footnotetext{
Received Nov. 11, 1991; revised Apr. 9, 1992; accepted Apr. 17, 1992.

This research was supported by NRSA Postdoctoral Fellowship NS08804 to E.G., NRSA Training Grant GM07524-15 to H.A.C. and C.S.W., and NIMH grant MH41256 to B.S.M.

Correspondence should be addressed to Elizabeth Gould, Ph.D., Laboratory of Ncuroendocrinology, The Rockefeller University, 1230 York Avenue, New York, NY 10021.

Copyright (c) 1992 Society for Neuroscience $0270-6474 / 92 / 123642-09 \$ 05.00 / 0$
}

born cells typically arise from the hilar region and travel to the granule cell layer as rapidly as $24 \mathrm{hr}$ following DNA synthesis (Cameron et al., 1991).

In most brain regions, radial glia are present only during development when they presumably guide migrating neurons to their appropriate destinations (Rakic, 1981). After this neuronal migration has been completed, radial glia are believed to differentiate into mature astrocytes (Pixley and de Vellis, 1984). Unlike the majority of neural systems, the rat dentate gyrus retains radial glia into adulthood (Kosaka and Hama, 1986; Rickmann et al., 1987). Although mature astrocytes exist in the adult granule cell layer, their numbers are low compared to other brain regions (Kosaka and Hama, 1986). This unique pattern of glial cell distribution is intriguing in that it may be related to the unusual neuronal characteristics of the adult dentate gyrus. For example, it is likely that radial glia persist into adulthood in order to provide guidance for newly born migrating granule cells.

An understanding of the factors that permit the persistance of typically developmental features, that is, cell birth, death, and the presence of radial glia, in the adult rate dentate gyrus is of considerable interest in our attempt to identify the cues that normally terminate these characteristics in other systems once development is complete. Since cell birth, death, and migration are generally considered to be developmental processes, it is likely that factors that regulate their occurrence during development continue to do so in adulthood. Several lines of evidence suggest that adrenal steroids mediate cell birth, survival, and migration in the dentate gyrus during development. First, maximal cell birth, death, and migration in the developing dentate gyrus occur during a time, called the stress hyperoresponsive period, when adrenal steroid levels are naturally low (Schlessinger et al., 1975; Rickmann et al., 1987; Gould et al., 1991 a; compare with Sapolsky and Meancy, 1986). Second, increasing the levels of adrenal steroids during the stress hyporesponsive period decreases the rate of cell birth (Bohn, 1980; Gould et al., 1991c), cell death (Gould et al., 1991b), and possibly cell migration in the dentate gyrus (see Gould et al., $1991 \mathrm{~b}, \mathrm{c}$, for commentary). Third, adrenalectomy toward the end of the stress hyporesponsive period, when adrenal steroids begin to rise naturally, increases the rate of both hippocampal cell division (Yehuda et al., 1989) and dentate gyrus cell death (Gould et al., 1991b).

Recent findings suggest that the survival of adult dentate gyrus cells depends on adrenal steroids (Sloviter et al., 1989; Gould et al., 1990a), indicating that these hormones continue to regulate certain developmental processes throughout adulthood. It is presently unknown precisely what types of dentate gyrus cells require adrenal steroids for their survival and whether cell birth 
in the adult dentate gyrus is also regulated by these hormones. In order to determine whether dentate gyrus neurons, glia, or both require adrenal steroids for their survival and whether the birth of dentate gyrus cells is mediated by adrenal hormones, we performed ${ }^{3} \mathrm{H}$-thymidine autoradiography, Nissl staining, and immunohistochemistry for the glial cell markers vimentin and glial fibrillary acidic protein (GFAP) as well as for the neuronal marker neuron-specific enolase (NSE), on brain tissue from control and hormonally manipulated adult rats.

\section{Materials and Methods}

Experiment 1: to determine whether the density of GFAP- and vimentin-immunoreactive cells changes with $A D X$ and whether $A D X$-induced pyknotic cells are GFAP, vimentin, or NSE immunoreactive

Animal treatments and histology. Adult ( 3 months) male Sprague-Dawley rats (Charles River) were group housed and provided with unlimited access to food and water. These rats were subjected to one of the following treatments: (1) sham operation, (2) bilateral adrenalectomy, or (3) bilateral adrenalectomy with corticosterone (CORT) replacement in the drinking water $(25 \mu \mathrm{g} / \mathrm{ml})$. This dose results in blood levels of CORT that are within the lower range of normal levels (Gould et al, 1990a). All surgery was performed using aseptic procedures under Metofane anesthesia. Adrenalectomized rats were provided with $0.9 \% \mathrm{NaCl}$ in the drinking water to maintain salt balance. Seven days following surgery, these rats were deeply anesthetized with Metofane and perfused with $120 \mathrm{ml}$ of $4.0 \%$ paraformaldehyde in $0.1 \mathrm{M}$ phosphate buffer with $1.5 \%(\mathrm{v} / \mathrm{v})$ picric acid. The brains were dissected from the skulls and postfixed overnight in the perfusion solution. Brain sections $40 \mu \mathrm{m}$ thick were cut on a Vibratome into a bath of PBS and reacted for either vimentin, GFAP, or NSE immunohistochemistry as described previously (Gould et al., 1990b). Briefly, the sections were placed in a solution of mouse monoclonal antibodies to vimentin (Boehringer Mannheim, diluted 1:50 in PBS), mouse monoclonal antibodies to GFAP (Boehringer Mannheim, diluted 1:50 in PBS), or rabbit polyclonal antibodies to NSE (Polysciences, diluted 1:2000 in PBS) overnight. The sections were then rinsed in PBS and transferred to a solution containing antimouse or anti-rabbit secondary antibodies (Vector laboratories, diluted 1:50 in PBS with horse or goat normal serum, respectively) for $2 \mathrm{hr}$. The sections were again rinsed in PBS and incubated for $2 \mathrm{hr}$ in avidinbiotin-HRP (Vector Laboratories, diluted I:50 in PBS). Following this, the sections were rinsed in PBS and reacted in a solution containing diaminobenzidine, hydrogen peroxide, and PBS for $15 \mathrm{~min}$. After a final rinse in PBS, the sections were mounted onto gelatinized slides, dried, rinsed in distilled water, dehydrated, cleared in Histoclear, and coverslipped under Permount. Prior to dehydration, some sections were counterstained for Nissl using cresyl violet. As immunohistochemical controls, the above procedures were performed with omission of the primary antibody incubation. Examination of this control tissue revealed no nonspecific staining of the secondary antibody. In an effort to maximize the reliability of comparisons within and between animals, vimentin, GFAP, and NSE immunohistochemistry were performed simultaneously on tissue from brains of all treatment groups.

Data analysis. The slides were coded prior to the analysis, and the code was not broken until the analysis was complete. For each brain, a minimum of six each of vimentin-immunostained and GFAP-immunostained sections were analyzed. Selected sections were located in the middle portion of the dentate gyrus. At this level, the dentate gyrus is located horizontally beneath the corpus callosum and the suprapyramidal and infrapyramidal blades are joined at the crest. The numbers of GFAP- and vimentin-immunoreactive cell bodies in the granule cell layer were counted by use of a light microscope $(400 \times)$. Included in these counts were immunoreactive cells with somata in the subgranular zone (the border between the granule cell layer and the hilus) and processes extending into the granule cell layer. The granule cell layer was then traced by use of a camera lucida drawing tube $(32 \times)$, and the crosssectional area of the layer was determined with a Zeiss Interactive Digitizing Analysis System (ZIDAS). The data were expressed as the number of immunoreactive cell bodies per $10^{\circ} \mu \mathrm{m}^{2}$. Means of thesc variables were determined for each animal, and the data were subjected to oneway ANOVA followed by Tukey HSD post hoc comparisons.
The percentages of pyknotic cells immunoreactive for vimentin, GFAP. and NSE were also determined by counting the numbers of immunoreactive and nonimmunoreactive pyknotic cells from a minimum of four sections for each antigen from each brain. Pyknotic cells were characterized by the lack of a nuclear membrane, light or absent cytoplasm, and the presence of darkly stained circular condensed chromatin (see Sengelaub and Finlay, 1982; Gould et al., 1991a, for examples).

\section{Experiment 2: to determine whether $4 D X$ alters the density of 'H-thymidine-labeled cells and whether these 'H-thymidine- labeled cells are GFAP, vimentin, or NSE immunoreactive}

Animal treatments and histology. Adult (4 months) male Sprague-Dawlcy rats (Charles River) were group housed and provided unlimited access to food and water. These rats were subjected to one of the following treatments: (1) sham operation or (2) bilateral adrenalectomy. All surgical procedures were performed using aseptic techniques under Metofane anesthesia. Adrenalectomized animals were provided with $0.9 \% \mathrm{NaCl}$ in the drinking water. On days 2,4 , and 6 following surgery, these rats received an intraperitoneal injection of $5.0 \mu \mathrm{Ci} / \mathrm{gm}$ body weight ${ }^{3} \mathrm{H}$-thymidine in water (New England Nuclear; specific activity, $80 \mathrm{Ci} / \mathrm{mmol}$ ). Twenty-four hours following the last injection, the rats were deeply anesthetized with Metofane and transcardially perfused as described for experiment 1 . This last survival interval was selected because it provides enough time for the uptake of thymidine and the completion of mitosis by granule cell ncuroblasts (Lewis, 1978). The brains were dissected from the cranial cavities and processed for vimentin, GFAP, and NSE immunohistochemistry as described above. After mounting onto gelatinized slides, the reacted sections were dried, rinsed in distilled water, and dipped in photographic emulsion (Kodak, NTB-2). The slides were stored in the dark at $4^{\circ} \mathrm{C}$ for 6 weeks. The slides were then developed (Kodak, Dektol), rinsed in distilled water, fixed (Kodak, Ektaflo), rinsed in running tap water, counterstained for Nissl using cresyl violet, dehydrated, cleared in Histoclear, and coverslipped under Permount.

Data analysis. The slides were coded prior to quantitative analysis, and the code was not broken until the analysis was finished. For each brain, a minimum of four sections each of vimentin-immunoreactive, GFAP-immunoreactive, and NSE-immunoreactive tissue were analyzed for this experiment. As indicated above, selected sections were located in the middle portion of the dentate gyrus. For each section, the numbers of immunoreactive and nonimmunoreactive ${ }^{3} \mathrm{H}$-thymidinelabeled cells were determined. These counts included cells with somata in the subgranular zone but not the hilus itself. The cross-sectional area of the granule cell layer was determined as described above, and these values were expressed as number of cells per $10^{6} \mu \mathrm{m}^{2}$. Means of these variables were determined for each animal, and the data were subjected to two-tailed Student's $t$ tests. In order to confirm the results of experiment 1 , the percentages of pyknotic cells immunoreactive for GFAP, vimentin, and NSE were also determined.

Experiment 3: to determine whether $A D X$ affects the density of ${ }^{3} H$-thymidine-labeled cells with glial and neuronal morphologies and to determine whether ADX alters the density of healthy cells

Animal treatments and histology. Adult (5 months) male Sprague-Dawley rats (Charles River) were group housed and provided unlimited access to food and water. These rats received either sham operation or bilateral adrenalectomy using aseptic procedures under Metofane anesthesia. Adrenalectomized rats received $0.9 \% \mathrm{NaCl}$ in the drinking water. All rats involved in this study received a single injection of 5.0 $\mu \mathrm{Ci} / \mathrm{gm}$ body weight of ${ }^{3} \mathrm{H}$-thymidine (New England Nuclear; specific activity, $80 \mathrm{Ci} / \mathrm{mmol}$ ) $6 \mathrm{~d}$ after surgery. Twenty-four hours after this injection, the rats were transcardially perfused as described above. This survival interval between injection and perfusion was selected because it provides adequate time for the uptake of thymidine by dividing cells and the completion of mitosis by granule cell neuroblasts (Lewis, 1978). After postfixation, these brains were placed in 30\% sucrose in PBS until they sank. The brains were then frozen on dry ice, and sections $18 \mu \mathrm{m}$ thick were cut on a cryostat and thaw mounted onto gelatinized slides. The slides were then dipped in photographic emulsion, incubated, and devcloped as described for cxpcriment 2 . The slides were Nissl stained using cresyl violet, dehydrated, cleared in Histoclear, and coverslipped under Permount. 


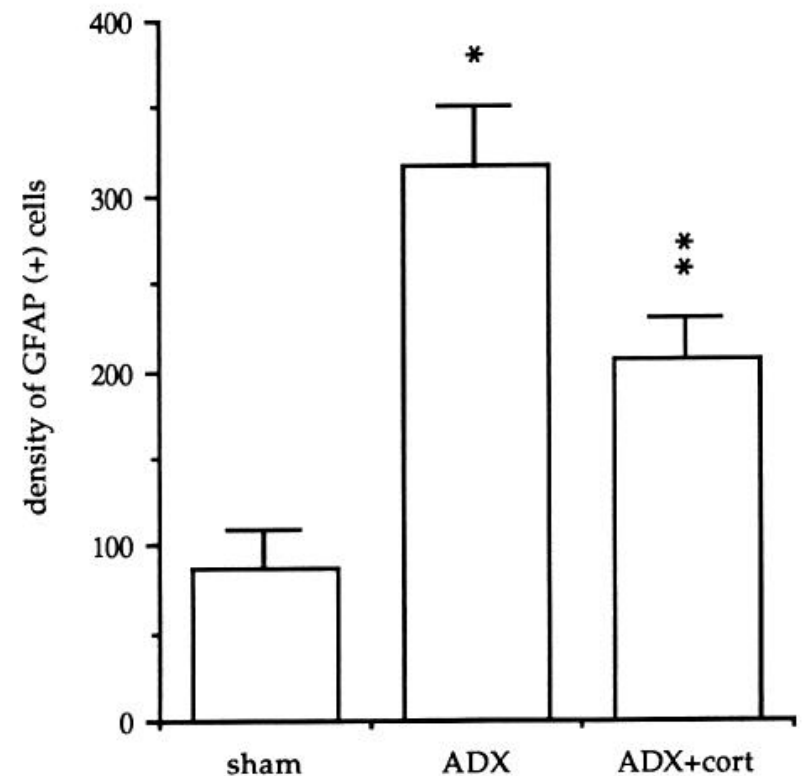

Figure 1. The density of GFAP-immunoreactive cell bodies (mean + SEM) in the granule cell layer of sham-operated, ADX, and ADX + CORT rats ( $n=6$ for each group). Single asterisk represents significant difference $(p<0.05$, one-way ANOVA followed by Tukey HSD post hoc comparisons) from both sham and ADX + CORT. Double asterisk represents significant difference $(p<0.05)$ from sham and ADX.

Data analysis. The slides were coded prior to light microscopic analysis, and the code was not broken until the analysis was complete. For each brain, a minimum of four sections were analyzed. In order to avoid the necessity of correcting for twice-counted cells, the selected sections were at least $36 \mu \mathrm{m}$ apart. For each selected section, the number of ${ }^{3} \mathrm{H}$ thymidine-labeled cells was determined. Each ${ }^{3} \mathrm{H}$-thymidine-labeled

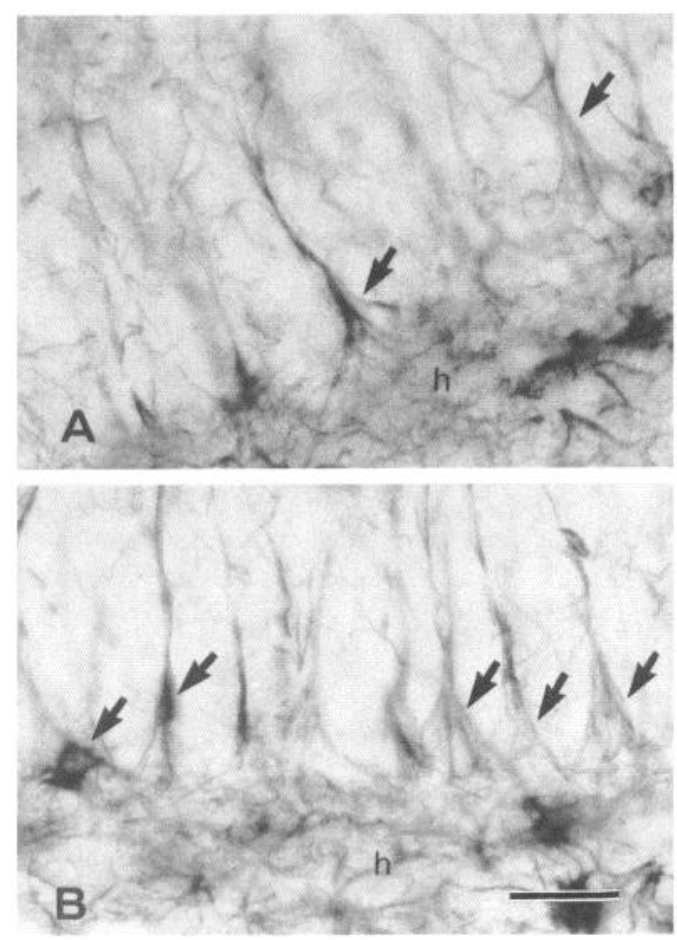

Figure 2. Photomicrographs of representative vimentin-immunoreactive cells (arrows) in the granule cell layer of sham-operated $(A)$ and ADX rats $(B)$. The density of these cells is greater in $B$ than $A$. Scale bar, $30 \mu \mathrm{m}$ for both $A$ and $B$.

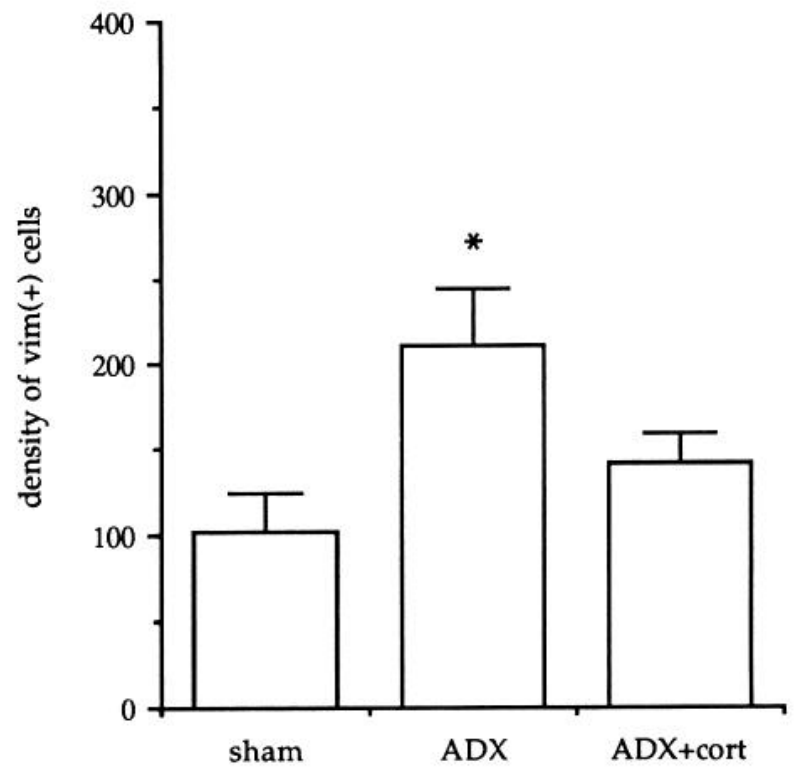

Figure 3. The density of vimentin-immunoreactive cell bodies (mean + SEM) in the granule cell layer of sham operated, ADX, and ADX + CORT rats ( $n=6$ for each group). Asterisk represents significant difference $(p<0.05$, one-way ANOVA followed by Tukey HSD post hoc comparisons) from both sham and ADX+CORT.

cell was rated as showing either glial morphology, i.e., small $\left(<70 \mu \mathrm{m}^{2}\right.$ cross-sectional cell body area) irregularly shaped cell bodies, or neuronal morphology, i.e., medium-sized ( $>70 \mu \mathrm{m}^{2}$ cross-sectional cell body area) round or oval shaped cell bodies. These criteria are likely to underestimate the number of neurons because newly born neurons may be smaller than mature ones and may be elongated during migration. In addition, the numbers of pyknotic and of healthy cells, that is, not pyknotic, within the granule cell layer were counted. A cell was counted as healthy if it showed a distinct boundary and appeared to be whole; cell fragments were not included in the analysis. The cross-sectional area of the granule cell layer was determined as described above, and the data were expressed as number of cells per $10^{6} \mu \mathrm{m}^{2}$. Means of the above-described variables were determined for each animal, and the data were subjected to two-tailed Student's $t$ tests.

\section{Results}

\section{Experiment 1}

Examination of the dentate gyrus from control brains revealed low numbers of GFAP-immunoreactive astrocytes in the granule cell layer compared to the surrounding regions. Quantitative analysis of the density of GFAP-immunoreactive cells in the granule cell layer revealed significant increases with adrenalectomy $(p<0.05$; Fig. 1$)$. CORT replacement to adrenalectomized rats prevented this increase in the density of GFAP-immunoreactive cells (Fig. 1).

Light microscopic examination of the dentate gyrus of control rats revealed vimentin-immunoreactive cells that appeared to be radial glia, that is, small cell bodies with radial processes (Fig. 2). The cell bodies of these glia were usually located in the subgranular zone, and their processes extended into the granule cell layer. Quantitative analysis of the density of vimentin-immunoreactive cell bodies in the dentate gyrus across treatment groups revealed significant overall differences ( $p<0.05$; Fig. 3). Specifically, adrenalectomy resulted in a significant increase in the number of vimentin-immunoreactive cells compared to sham operation (Figs. 2, 3). CORT replacement to adrenalectomized rats prevented this increase in vimentin-immunoreactive cells (Fig. 3). 

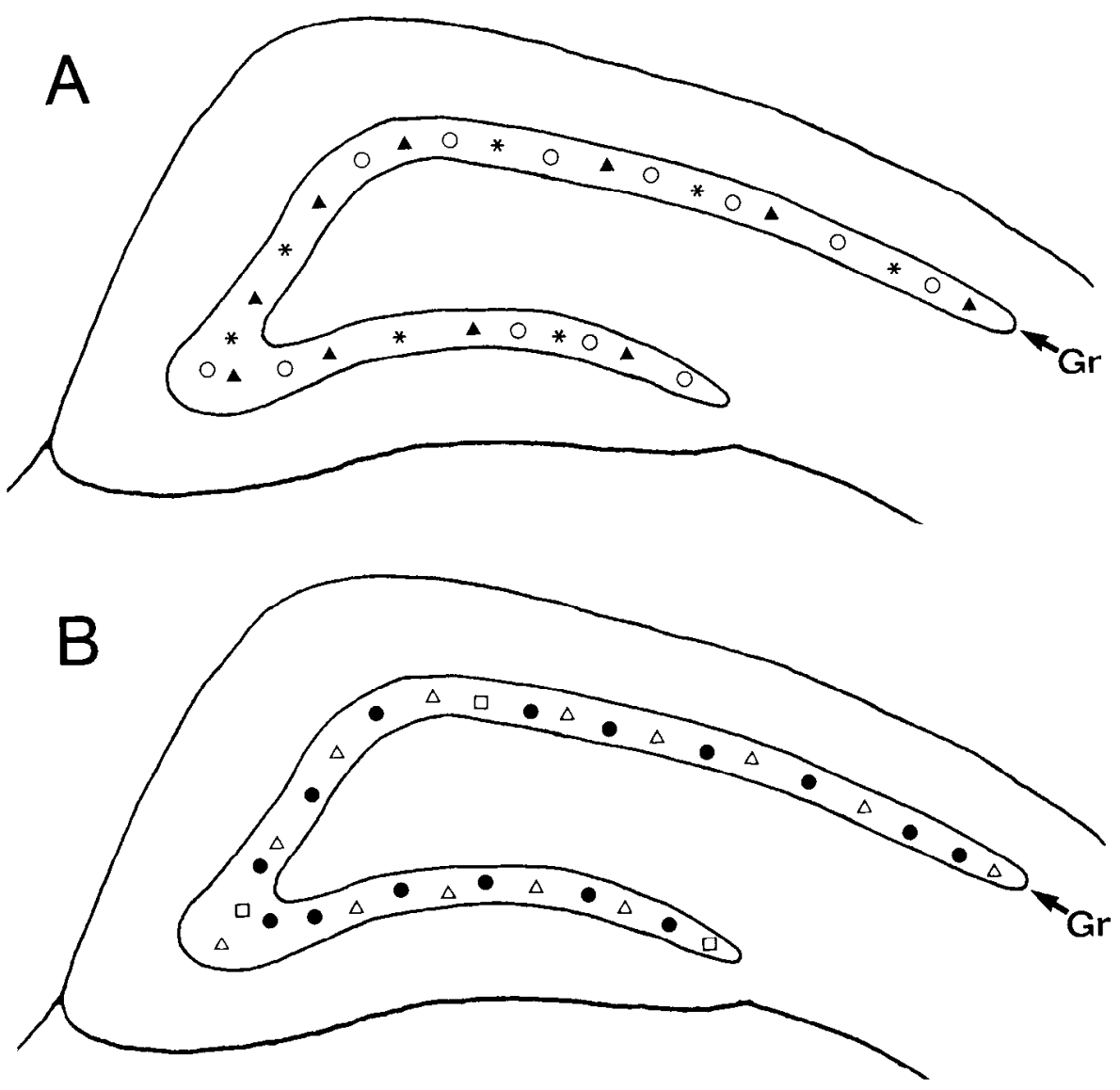

Figure 4. Templates showing the cellular identity and distribution of pyknotic cells $(A)$ and ${ }^{3} \mathrm{H}$-thymidine-labeled cells $(B)$ in the granule cell layer $(G r)$ of ADX rats. Solid triangles represent vimentin-immunoreactive pyknotic cells, asterisks represent NSE-immunoreactive pyknotic cells, open circles represent nonimmunoreactive pyknotic cells ( 1 symbol -5 pyknotic cells). Open triangles represent vimentin-immunoreactive ${ }^{3} \mathrm{H}$-thymidine-labeled cells, open squares represent GFAP-immunoreactive ${ }^{3} \mathrm{H}$-thymidine-labeled cells, solid circles represent nonimmunoreactive ${ }^{3} \mathrm{H}$-thymidine-labeled cells ( 1 symbol $=1{ }^{3} \mathrm{H}$-thymidine-labeled cell). These values represent the mean number of each cell type for a single section.
As previously reported (see Gould et al., 1990a), quantitative analysis of the density of pyknotic cells revealed a large increase with adrenalectomy that was prevented with CORT treatment (mean number of pyknotic cells $/ 10^{6} \mu \mathrm{m}^{2}=3.8 \pm 1.0$ for sham, $519.4 \pm 189.6$ for ADX, $4.9 \pm 0.7$ for ADX + CORT). In addition, a general relationship between the magnitude of pyknosis and the density of GFAP- and vimentin-positive cells was observed. The brains that showed the greatest density of pyknotic cells were the brains that showed the greatest density of GFAP- and vimentin-immunoreactive cells. Examination of immunoreactive tissue from adrenalectomized rats counterstained for Nissl revealed some pyknotic cells that were immunoreactive for vimentin (approximately 35\% of the total number of pyknotic cells), some pyknotic cells that were immunoreactive for NSE (approximately $25 \%$ of the total number of pyknotic cells), and no examples of GFAP-immunoreactive pyknotic cells (Fig. 4).

\section{Experiment 2}

In control brains, a small but significant number of vimentinimmunoreactive ${ }^{3} \mathrm{H}$-thymidine-labeled cells that appeared to be radial glia were observed in the dentate gyrus (Figs. 5, 6). Quantitative analysis of vimentin-immunoreactive ${ }^{3} \mathrm{H}$-thymidine-labeled cells revealed a significant increase with adrenalectomy $\left(p<0.05\right.$; Fig. 6). The distribution of ${ }^{3} \mathrm{H}$-thymidinelabeled vimentin-immunoreactive cells was no different from that observed for non-thymidine-labeled vimentin-immunoreactive cells; cell bodies were typically located in the subgranular zone with processes extending through the granule cell layer.
Moreover, despite the dramatic increase in ${ }^{3} \mathrm{H}$-thymidine-labeled cells with adrenalectomy, no difference in the distribution of these cells was observed with treatment. The number of ${ }^{3} \mathrm{H}$ thymidine-labeled cells in these same sections that were not immunoreactive for vimentin determined from these same sections also increased with adrenalectomy $(p<0.05$; Figs. 5, 6) In contrast, no change in the number of GFAP-immunoreactive ${ }^{3} \mathrm{H}$-thymidine-labeled cells was observed with adrenalectomy $\left(p>0.1\right.$; Fig. 7). The number of ${ }^{3} \mathrm{H}$-thymidine-labeled cells that were not immunoreactive for GFAP increased appreciably with adrenalectomy ( $p<0.05$; Fig. 7). In addition, as seen for experiment 1 , the number of GFAP-immunoreactive cells that were not labeled with ${ }^{3} \mathrm{H}$-thymidine was much greater in brains of adrenalectomized rats compared to controls.

Light microscopic examination of NSE-immunoreactive ${ }^{3} \mathrm{H}$ thymidine-labeled tissue revealed no double labeled cells in the dentate gyrus of either sham-operated or adrenalectomized animals. However, many ${ }^{3} \mathrm{H}$-thymidine-labeled cells showed neuronal characteristics and were not immunoreactive for glial cell markers (Fig. 5). The numbers of these profiles increased with adrenalectomy (Fig. 4).

As shown for experiment 1, no GFAP-immunoreactive pyknotic cells were observed in brains of either sham operated or adrenalectomized rats but many of the pyknotic cells in the latter treatment group were vimentin immunoreactive (approximately $35 \%$ ) or NSE immunoreactive (approximately $25 \%$ ) (Fig. 4). Although an occasional ${ }^{3} \mathrm{H}$-thymidine-labeled cell was pyknotic, no change in these profiles was observed with adrenalectomy. In no instance were vimentin-, NSE-, or GFAP-immunoreactive ${ }^{3} \mathrm{H}$-thymidine-labeled pyknotic cells observed. 
Figure 5. Photomicrographs of representative ${ }^{3} \mathrm{H}$-thymidine-labeled cells (long arrows) that are vimentin-positive $(A)$ and vimentin-negative $(B)$ from the adult rat dentate gyrus. Short arrow in $B$ indicates a pyknotic cell. Scale bar, $20 \mu \mathrm{m}$ for both $A$ and $B$.
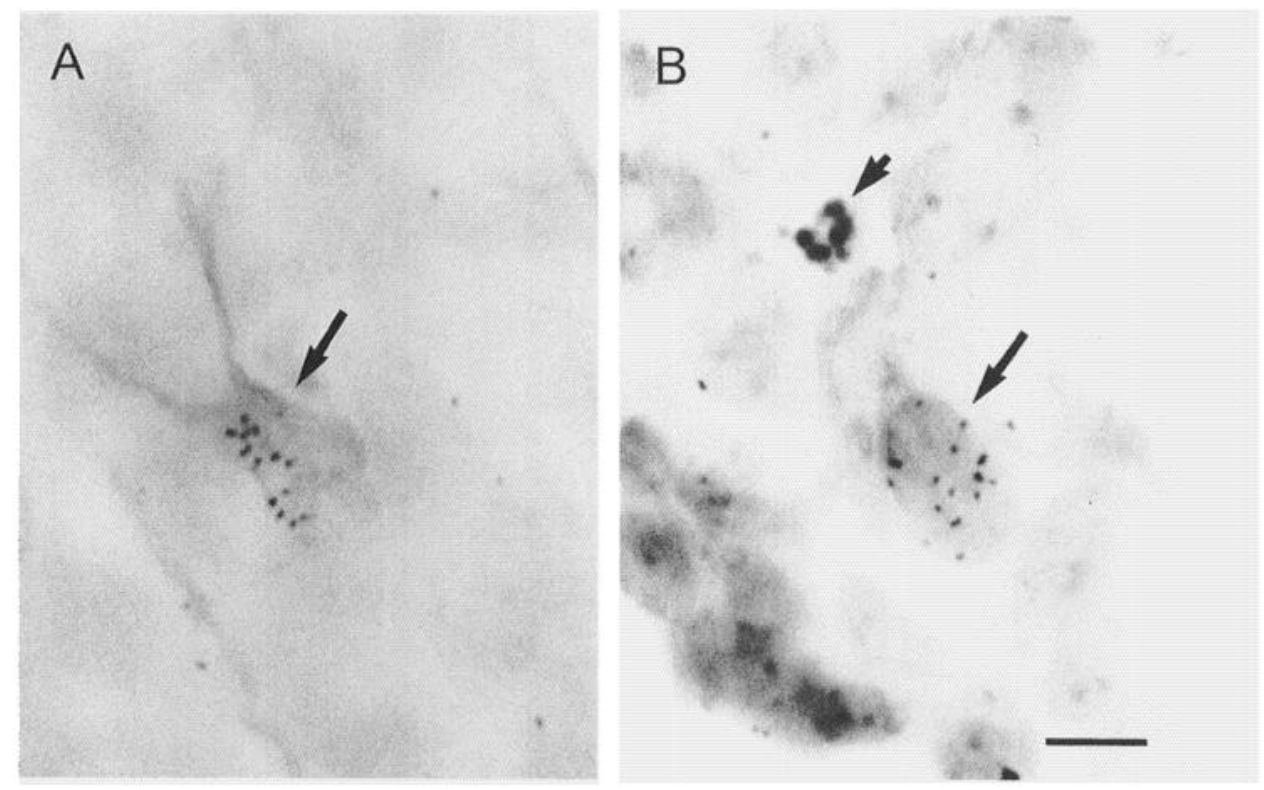

\section{Experiment 3}

Light microscopic examination of ${ }^{3} \mathrm{H}$-thymidine-labeled Nisslstained thin sections revealed labeled cells scattered throughout the dentate gyrus. The majority of these labeled cells were located in the subgranular zone, with fewer seen in the hilus or the granule cell layer itself. In sham-operated brains, approximately $65 \%$ of all labeled cells showed glial morphologies, that is, small, irregularly shaped cell bodies, whereas the remaining ${ }^{3} \mathrm{H}$-thymidine-labeled cells (approximately 35\%) showed neuronal characteristics, that is, medium sized round or oval cell bodies (Fig. 8). The density of ${ }^{3} \mathrm{H}$-thymidine-labeled cells increased with adrenalectomy $(p<0.05$; Fig. 9). Despite this observation, no change in the proportion of labeled cells with neuronal versus glial morphologies was observed. In addition, the number of healthy cells showed a slight but significant decrease with adrenalectomy $(p<0.05$; Fig. 10). The results of experiments 1-3 are summarized in Table 1.

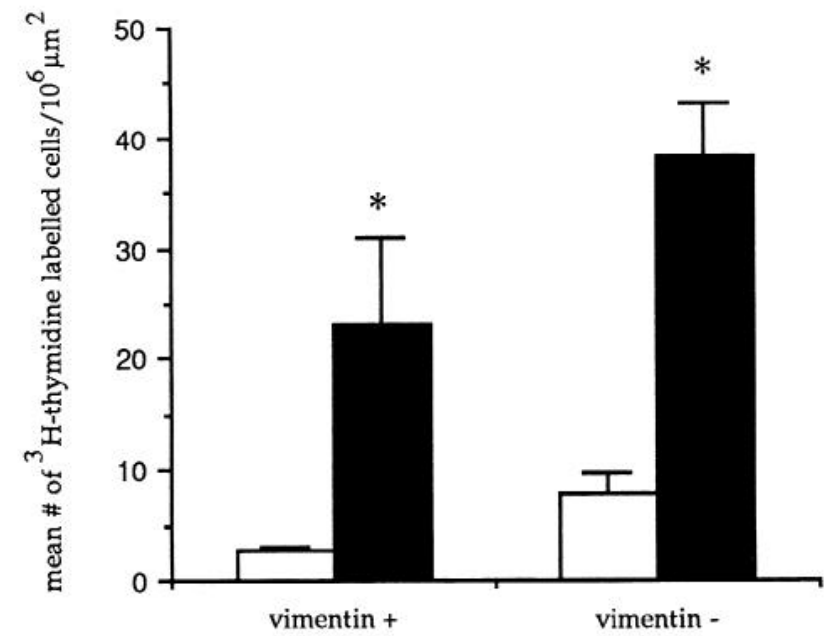

Figure 6. Density of ${ }^{3} \mathrm{H}$-thymidine-labeled cells (mean + SEM) that are immunoreactive for vimentin and ${ }^{3} \mathrm{H}$-thymidine-labeled cells that are vimentin-negative in the dentate gyrus of sham-operated (open bar) and ADX (solid bar) rats ( $n=5$ for each group). Asterisks represent significant difference ( $p<0.05$, Student's $t$ tests) from sham value for same cell type.

\section{Discussion}

The results of this study show that removal of adrenal hormones results in numerous cellular changes in the adult rate dentate gyrus. Adrenalectomy results in an increase in the density of GFAP- and vimentin-immunoreactive cells; this effect can be prevented by providing CORT replacement. Adrenalectomy also results in an increase in the numbers of both degenerating cells and newly born cells in the dentate gyrus; these populations are probably comprised of both glia and neurons (see Table 1 for summary).

\section{Identity of pyknotic cells in the adult dentate gyrus}

The results of this report indicate that the population of cells that degenerates with adrenalectomy comprises neurons and glia, but not mature astrocytes. Our previous studies have shown that adrenalectomy results in a dramatic increase in the density

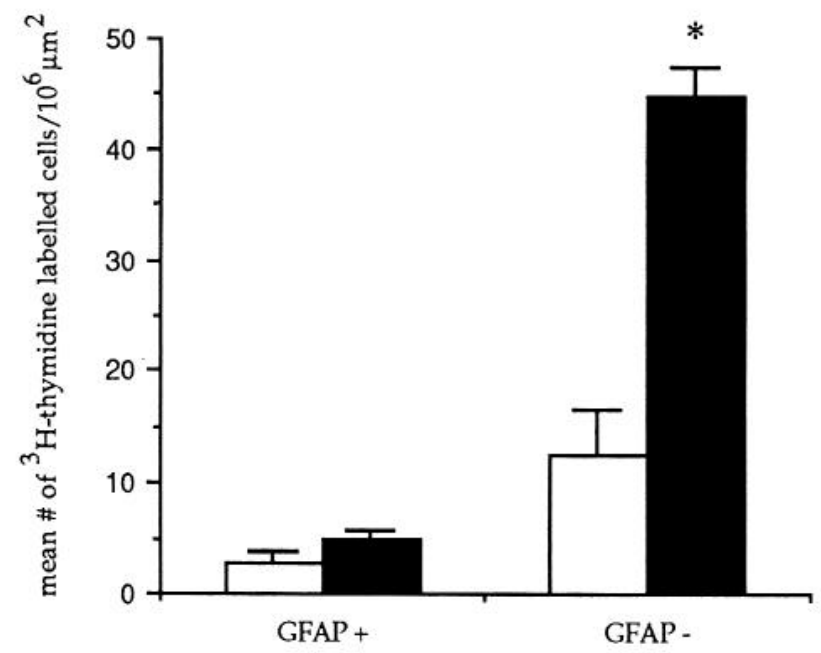

Figure 7. Density of ${ }^{3} \mathrm{H}$-thymidine-labeled cells (mean + SEM) that are GFAP-positive and ${ }^{3} \mathrm{H}$-thymidine labeled cells that are GFAP-negative in the dentate gyrus of sham-operated (open bar) and ADX (solid bar) rats ( $n=5$ for each group). Asterisk represents significant difference ( $p<0.05$, Student's $t$ tests) from sham value for same cell type. 

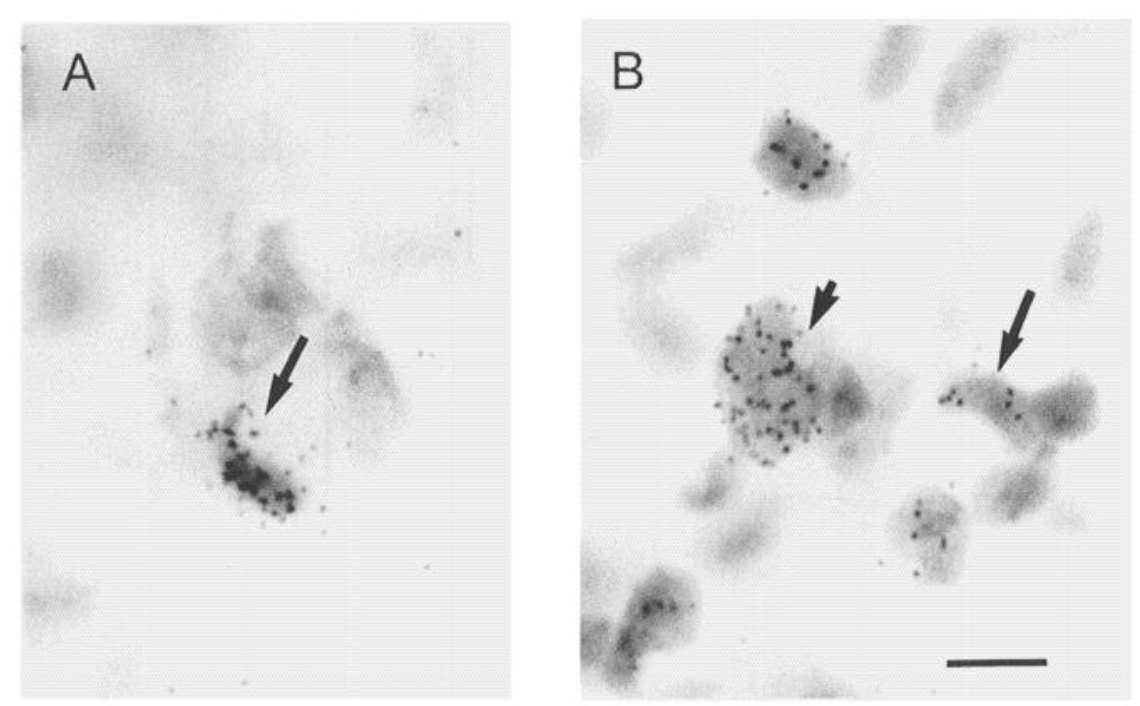

Figure 8. Photomicrographs of representative ${ }^{3} \mathrm{H}$-thymidine-labeled Nissl-stained cells showing morphology characteristic of glia (long arrows) and neurons (short arrow). Scale bar, 20 $\mu \mathrm{m}$ for both $A$ and $B$. of pyknotic cells in the granule cell layer (Gould et al., 1990a; Woolley et al., 1991). Although these degenerating cells were observed in the granule cell layer, a region that contains a relatively low density of glial cells (Kosaka and Hama, 1986), it was unknown whether these pyknotic cells were glial or neuronal. A single-section Golgi study indicating that adrenalectomy results in a decrease in the number of dendritic branch points and cell body area of granule cells (Gould et al., 1990a) suggests that neurons are in fact degenerating. The results of the present study showing that some pyknotic cells express NSE provides direct evidence to support this contention. The data reported here showing that adrenalectomy results in a net increase in GFAP-immunoreactive and vimentin-immunoreactive cells and a net decrease in total cells also support the notion that most degenerating cells are neurons. However, the presence of a large proportion of vimentin-immunoreactive pyknotic cells (approximately $35 \%$ of all pyknotic cells) indicates that many glial cells are dying as well. It is likely that the vimentin-im-

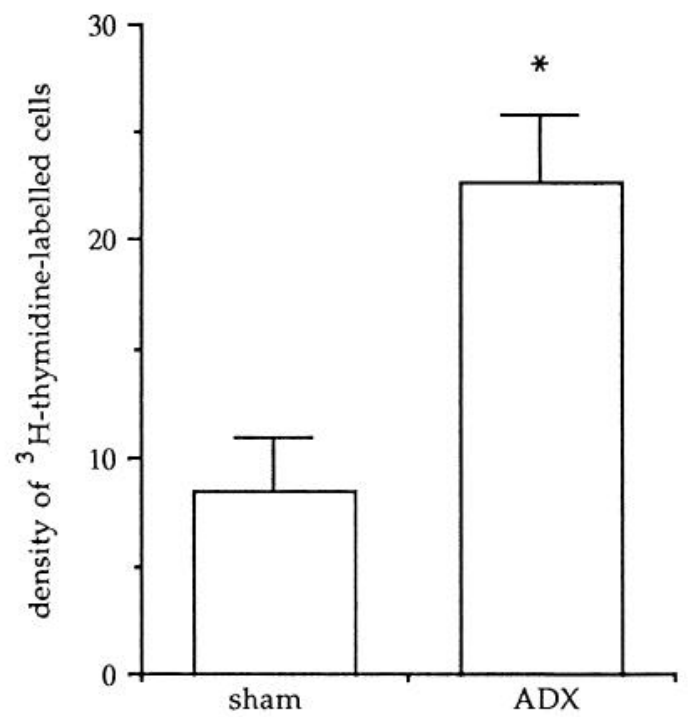

Figure 9. Density of ${ }^{3} \mathrm{H}$-thymidine-labeled cells $($ mean + SEM) in the granule cell layer of Nissl-stained tissue from sham-operated and ADX rats ( $n=5$ for each group). Asterisk represents significant difference ( $p$ $<0.05$, Student's $t$ test) from sham. munoreactive cells that are degenerating represent a separate population of glial cells from those that are dividing in response to adrenalectomy since no examples of vimentin-immunoreactive ${ }^{3} \mathrm{H}$-thymidine-labeled pyknotic cells were observed. Although many pyknotic cells appear to be vimentin immunoreactive or NSE immunoreactive, a large proportion of these degenerating cells were not immunoreactive for either antigen. Although the identity of these pyknotic cells is unknown, it is likely that cells become nonimmunoreactive for antigens they previously expressed as degeneration proceeds.

\section{Identity of ${ }^{3} \mathrm{H}$-thymidine labeled cells in the adult dentate gyrus}

The results of this study indicate that the population of ${ }^{3} \mathrm{H}$ thymidine-labeled cells in the adult rat dentate gyrus comprises both glia and neurons. Since GFAP has been shown to be a marker for mature astrocytes (Pixley and de Vellis, 1984), it is

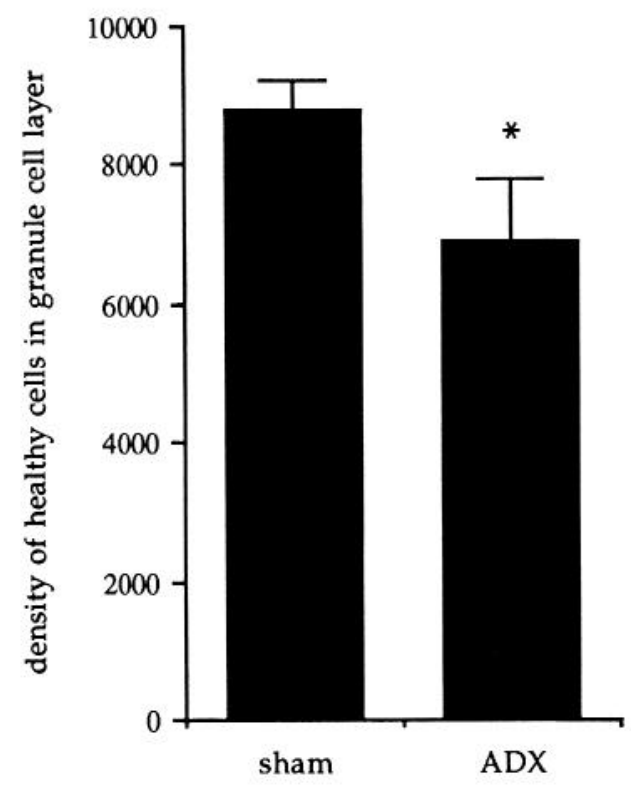

Figure 10. Density of healthy cells (mean + SEM) in the granule cell layer of Nissl-stained tissue from sham-operated and ADX rats $(n=5$ for each group). Asterisk represents significant difference $(p<0.05$, Student's $t$ test) from sham. 


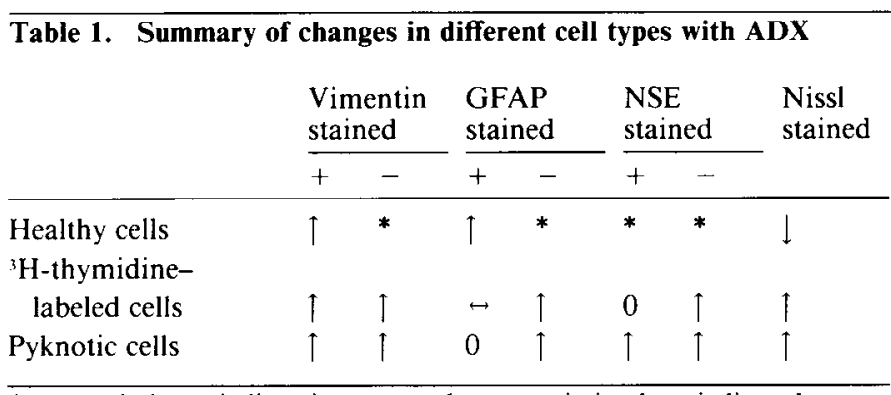

Arrows pointing up indicate increases and arrows pointing down indicate decreases in the density of this cell type with ADX. Horizontal arrows indicate no change in this cell type with ADX. Zeros indicate no cells of this particular type observed, and asterisks represent no data collected for this cell type.

likely that the small number of GFAP-immunoreactive ${ }^{3} \mathrm{H}$ thymidine-labeled cells observed in this study are glia. Vimentin has been shown to be a marker for immature glial cells (Pixley and de Vellis, 1984). The majority of ${ }^{3} \mathrm{H}$-thymidine-labeled vimentin-immunoreactive cells observed in our study possessed radial glial morphologies: small cell bodies with thin processes radiating through the granule cell layer. Recent studies performed in the neural pathways mediating canary bird song have led to the suggestion that radial glia differentiate into neurons (see Alvarez-Buylla, 1990, for commentary). Future time course studies will be required in order to determine whether decreases in the number of ${ }^{3} \mathrm{H}$-thymidine-labeled radial glia coincide with increases in the number of ${ }^{3} \mathrm{H}$-thymidine-labeled neurons in the adult rat dentate gyrus.

Although it is likely that the ${ }^{3} \mathrm{H}$-thymidine-labeled cells that are immunoreactive for GFAP and vimentin are glial cells, it is not clear what population of cells is represented by the ${ }^{3} \mathrm{H}$ thymidine-labeled nonimmunoreactive cells. It is likely that a substantial proportion of the ${ }^{3} \mathrm{H}$-thymidine-labeled GFAP-negative cells represent vimentin-immunoreactive cells. However, it is not likely that a substantial proportion of the dividing vimentin-negative cells represent GFAP-immunoreactive cells because the number of vimentin-negative ${ }^{3} \mathrm{H}$-thymidine-labeled cells dramatically increased with adrenalectomy whereas the number of GFAP-immunoreactive ${ }^{3} \mathrm{H}$-thymidine-labeled cells remained very low.

Previous studies have shown that neurons are generated in the adult rat dentate gyrus (Kaplan and Hinds, 1977; Kaplan and Bell, 1984). In the normal adult rat dentate gyrus, ${ }^{3} \mathrm{H}$ thymidine-labeled cells have been shown to possess synapses (Kaplan and Hinds, 1977; Kaplan and Bell, 1984) and to extend axons into target sites (Trice and Stanfield, 1986). Since many of the ${ }^{3} \mathrm{H}$-thymidine-labeled nonimmunoreactive cells observed in the present study are relatively large and show neuronal morphologies, it is likely that at least some of these cells are neurons. It is possible that the low level of neurogenesis that normally occurs in the rat dentate gyrus is increased by adrenalectomy. Although the absence of any NSE-immunoreactive ${ }^{3} \mathrm{H}$-thymidine-labeled cells in this experiment weighs against this hypothesis, it is important to note that, during development, neurons do not express NSE until migration is complete and mature synaptic connections are formed (Schmechel et al., 1980). Since the longest interval between ${ }^{3} \mathrm{H}$-thymidine injection and perfusion in this study was less than 1 week, it is likely that more time is required for newly born neurons to express this protein in this system. Indeed, preliminary evidence from our laboratory suggests that by 1 month following ${ }^{3} \mathrm{H}$-thymidine injection many ${ }^{3} \mathrm{H}$-thymidinc-labcled cells in the normal adult rat dentate gyrus are NSE immunoreactive (H. A. Cameron and E. Gould, unpublished observation). Whether a similar time lag exists for NSE expression in the adrenalectomized rat dentate gyrus remains to be determined.

\section{Functional significance of changes in GFAP-immunoreactive cells}

Since adrenalectomy results in degeneration of cells in the granule cell layer (Gould et al., 1990a), it is possible that the increase in the density of GFAP-immunoreactive cells that we noted in this brain region is an astrocytic reaction to neuronal death. Astrocytes have been shown to migrate, hypertrophy, and/or divide in response to neuronal damage (Smith et al., 1986). The reaction of astrocytes in response to neuronal damage is thought to be an important step in the removal of cellular debris. The timing of adrenalectomy-induced increases in GFAP mRNA is consistent with this possibility; the onset of increased pyknosis in the granule cell layer precedes the increase in hippocampal GFAP mRNA (Gould et al., 1990a; compare with Nichols et al., 1990). It is unlikely that the increase in GFAP-immunoreactive cells is due to the division of astrocytes since we found no increase in the number of ${ }^{3} \mathrm{H}$-thymidine-labeled GFAP-immunoreactive cells with adrenalectomy. However, the possibility exists that these cells either migrate into the dentate gyrus or express higher levels of GFAP in response to neuronal damage.

Alternatively, there is some evidence to suggest that the increase in GFAP-immunoreactive cells is independent of neuronal damage. In brain regions that do not show an increase in the density of pyknotic cells with adrenalectomy, that is, the cerebellum (see McEwen and Gould, 1990), GFAP and GFAP mRNA levels are elevated by adrenalectomy (O'Callaghan et al., 1989; Nichols et al., 1990). Future studies will be required in order to determine whether the increase in density of GFAPimmunoreactive cell bodies observed in the dentate gyrus after adrenalectomy occurs independently of neuronal damage.

\section{Functional significance of changes in vimentin-immunoreactive cells}

Vimentin is expressed by radial glia and other immature glial cells that will, in most cases, differentiate into mature astrocytes with time (Pixley and de Vellis, 1984). Unlike most other brain regions, the dentate gyrus retains radial glia into adulthood. The cell bodies of these glia reside in the subgranular zone and their radial processes extend into the granule cell layer (Kosaka and Hama, 1986; Rickmann et al., 1987). A number of studies have shown that granule cells are born in the subgranular zone during adulthood (Kaplan and Hinds, 1977; Kaplan and Bell, 1984; Crespo et al., 1986). Although the function of radial glia in the adult dentate gyrus is presently unknown, it is likely that they subserve a similar function in adulthood as observed developmentally: to provide a substrate for the migration of newly born granule cells (Rickmann et al., 1987).

The results of this study show that the adrenalectomy-induced increase in the number of vimentin-immunoreactive radial glia is due to an increase in the birth of these cells. It is possible that the adrenalectomy-induced increase in the density of radial glia observed in this study is related to an increase in the birth of new granule cells. This hypothesis is supported by the fact that, during development, the appearance of a new set of radial glia usually precedes each period of increased neurogenesis in the 
dentate gyrus (Rickmann et al., 1987). Furthermore, developmental studies have shown that administration of adrenal steroids inhibits the birth of granule cells (Bohn, 1980; Gould et al., 1991c), suggesting that these hormones may suppress granule cell birth in adulthood as well. The observations of the present study that the density of cells with granule neuron morphology that are not immunoreactive for glial cell markers increases in response to adrenalectomy support this possibility. Studies aimed at positively identifying as neurons this third population of ${ }^{3} \mathrm{H}$ thymidine-labeled cells, that is, those that are not immunoreactive for GFAP or vimentin, are ongoing in our laboratory.

\section{The relationship between cell birth and cell death in the adult rat dentate gyrus}

The rat dentate gyrus shows ongoing cell birth and death into adulthood (Kaplan and Hinds, 1977; Kaplan and Bell, 1984; Gould et al., 1990a). Both newly born cells and pyknotic cells appear most commonly in the subgranular zone of the dentate gyrus (Crespo et al., 1986; Gould et al., 1990a), raising the possibility that they represent the same population of cells. If these cells simply turn over, it would follow that cell birth and death in the adult rat dentate gyrus do not affect the total number of granule cells. However, studies of granule cells during adult life have shown that these neurons increase in number up until at least 12 months of life (Bayer et al., 1982; Bayer, 1982; but see Boss et al., 1985), indicating that cell hirth normally outweighs cell death in this region. The results of this study show that removal of circulating adrenal hormones upsets this relationship; adrenalectomy results in a slight but significant net decrease in healthy granule cells after $7 \mathrm{~d}$, indicating that cell death outweighs cell birth.

Developmental studies have shown that even small numbers of pyknotic cclls usually reflect a high magnitude of cell loss due to rapid clearing of cellular debris. Given the magnitude of the pyknosis observed in this and our previous studies (Gould et al., 1990a; Woolley et al., 1991), it is surprising that a greater decrease in the number of healthy cells was not observed. This study indicates that the slight decrease observed probably reflects a compensatory increase in the rate of cell birth that partially offsets the increased cell death. The results of Sloviter et al. (1989) showed that adrenalectomy can result in complete obliteration of the granule cell layer at 3-4 months following surgery. This suggests that, with time, the discrepancy between cell death and cell birth continues such that by $3-4$ months, neuroblasts would no longer be able to replace dead granule cells. Future studies will be necessary to determine the rate of cell death and birth at different times after adrenalectomy.

\section{The role of adrenal hormones in the suppression of cell death and cell survival}

The results of this study and previous studies (Gould et al., 1990a; Woolley et al., 1991) show that the increase in pyknotic cells and GFAP-immunoreactive and vimentin-immunoreactive cells with adrenalectomy is due to the removal of circulating adrenal steroids and not due to the removal of catecholamines. Replacement of CORT in the drinking water of adrenalectomized rats prevents the increase in density of pyknotic cells and GFAP-immunoreactive and vimentin-immunoreactive cells in the dentate gyrus. We have previously shown that type 1 adrenal steroid receptors are involved in the adrenalectomy-induced pyknosis; replacement with the type 1 receptor agonists CORT or aldosterone prevent this effect, whereas replacement with the type 2 receptor agonist RU28362 does not prevent this effect (Woolley et al., 1991). Although it is likely that the adrenalectomy-induced increase in ${ }^{3} \mathrm{H}$-thymidine-labeled vimentin-immunoreactive cells is dependent on activation of the type 1 receptor, that is, because low doses of CORT prevented the increase in vimentin-immunoreactive cells, it is unknown whether activation of the type 1 receptor will block the increase in nonimmunorcactive ${ }^{3} \mathrm{H}$-thymidinc-labeled cells. Futurc studies will be required to determine which adrenal hormone and receptor type normally prevents division of cells that do not express vimentin in the intact rat.

Under normal circumstances, the adult rat dentate gyrus shows a slow but steady level of cell birth and cell death. Bilateral removal of the adrenal glands results in markedly increased rates of both of these processes (Gould et al., 1990a; present results), suggesting that cell birth and death are normally suppressed by adrenal hormones. This contention is consistent with developmental findings that postnatal cell birth and death in the rat dentate gyrus are maximal at a time when adrenal hormone levels are exceedingly low (Schlessinger et al., 1975; Bayer, 1980; Gould et al., 1991a; compare with Sapolsky and Meaney, 1986). Experimentally induced increases in adrenal hormones during this postnatal period diminish both cell birth and cell death (Bohn, 1980; Gould ct al., 1991b,c). As the adrenal gland matures and circulating levels of its hormones rise, the rates of cell hirth and cell death taper off. The findings of this report show that developmental levels of both cell birth and cell death can be reinitiated by removing the adrenal glands. This suggests that adrenal hormones are the natural signal for the inhibition of developmental processes, such as cell birth and death in adult rat dentate gyrus.

\section{References}

Alvarez-Buylla A (1990) Mechanism of neurogenesis in adult avian brain. Experientia 46:948-955.

Bayer SA (1980) Development of the hippocampal region in the rat. I. Neurogenesis examined with ${ }^{3} \mathrm{H}$-thymidine autoradiography. J Comp Neurol 190:87-114.

Bayer SA (1982) Changes in the total number of dentate granule cells in juvenile and adult rats: a correlated volumetric and ${ }^{3} \mathrm{H}$ thymidine autoradiographic study. Exp Brain Res 46:315-323.

Bayer SA, Yackel JW, Puri PS (1982) Neurons in the rat dentate gyrus granular layer substantially increase during juvenile and adult life Science 216:890-892.

Bohn MC (1980) Granule cell genesis in the hippocampus of rats treated neonatally with hydrocortisone. Neuroscience 5:2003-2012.

Boss BD, Peterson GM, Cowan WM (1985) On the number of neurons in the dentate gyrus of the rat. Brain Res 338:144-150.

Cameron HA, Gould E, Daniels DC, McEwen BS (1991) Evidence for rapid migration of newly born cells in the adult rat dentate gyrus. Soc Neurosci Abstr 17:205.

Crespo D, Stanfield BB, Cowan WM (1986) Evidence that late-generated granule cells do not simply replace earlier formed neurons in the rat dentate gyrus. Exp Brain Res 62:541-548.

Gould E, Woolley CS, McEwen BS (1990a) Short-term glucocorticoid manipulations affect neuronal morphology and survival in the adult dentate gyrus. Neuroseience 37:367-375.

Gould E, Frankfurt M, Westlind-Danielsson A, McEwen BS (1990b) Developing forebrain astrocytes are sensitive to thyroid hormone. Glia 3:283-292.

Gould E, Woolley CS, McEwen BS (1991a) Naturally occurring cell death in the developing dentate gyrus of the rat. J Comp Neurol 304: $408-418$.

Gould E, Woolley CS, McEwen BS (1991b) Adrenal steroids regulate postnatal development of the rat dentate gyrus. I. Effects of glucocorticoids on cell death. J Comp Neurol 313:479-485.

Gould E, Woolley CS, Cameron HA, Daniels DC, McEwen BS (1991c) 
Adrenal steroids regulate postnatal development of the rat dentate gyrus. II. Effects of glucocorticoids and mineralocorticoids on cell birth. J Comp Neurol 313:486-493.

Kaplan MS, Bell DH (1984) Mitotic neuroblasts in the 9 day old and 11 month old rodent hippocampus. J Neurosci 4:1429-1441.

Kaplan MS, Hinds JW (1977) Neurogenesis in the adult rat: electron microscopic analysis of light radioautographs. Science 197:1092-1094.

Kosaka T, Hama K (1986) Three-dimensional structure of astrocytes in the rat dentate gyrus. J Comp Neurol 249:242-260.

Lewis PD (1978) Kinetics of cell proliferation in the postnatal rat dentate gyrus. Neuropathol Appl Neurobiol 4:191-195.

McEwen BS, Gould E (1990) Adrenal steroid influences on the survival of hippocampal neurons. Biochem Pharmacol 40:2393-2402.

Nichols NR, Osterburg HH, Masters JN, Millar SL, Finch CE (1990) Messenger KNA for glial fibrillary acidic protein is decreased in rat brain following acute and chronic corticosterone treatment. Mol Brain Res 7:1-7.

O'Callaghan JP, Brinton RE, McEwen BS (1989) Glucocorticoids regulate the concentration of glial fibrillary acidic protein throughout the brain. Brain Res 494:159-161.

Pixley SKR, de Vellis J (1984) Transition between immature radial glia and mature astrocytes studied with a monoclonal antibody to vimentin. Dev Brain Res 15:201-209.

Rakic P (1981) Neuronal-glial interaction during brain development. Trends Neurosci 4:184-187.

Rickmann M, Amaral DG, Cowan WM (1987) Organization of radial glial cells during the development of the rat dentate gyrus. J Comp Neurol 264:449-479.
Sapolsky RM, Meaney MJ (1986) Maturation of the adrenocortical stress response: neuroendocrine control mechanisms and the stress hyporesponsive period. Brain Res Rev 11:65-76.

Schlessinger AR, Cowan WM, Gottlieb DI (1975) An autoradiographic study of the time of origin and the pattern of granule cell migration in the dentate gyrus of the rat. J Comp Neurol 159:149-176.

Schmechel DE, Brightman MW, Marangos PJ (1980) Neurons switch from non-neuronal enolase to neuron-specific enolase during differentiation. Brain Res 190:195-214.

Sengelaub DR, Finlay BL (1982) Cell death in the mammalian visual system during normal development. I. Retinal ganglion cells. J Comp Neurol 204:311-317.

Sloviter RS, Valiquette G, Abrams GM, Ronk EC, Sollas AI, Paul LA, Neubort SL (1989) Selective loss of hippocampal granule cells in the mature rat brain after adrenalectomy. Science 243:535-538.

Smith GM, Miller RH, Silver J (1986) Changing role of forebrain astrocytes during development, regenerative failure and induced regeneration upon transplantation. J Comp Neurol 251:23-43.

Trice JE, Stanfield BB (1986) Evidence for the generation in the adult rat dentate gyrus of neurons that extend axonal projections. Ann Neurol 20:392.

Woolley CS, Gould E, Sakai RR, Spencer RL, McEwen BS (1991) Effects of aldosterone or RU28362 treatment on adrenalectomy-induced cell death in the dentate gyrus of the adult rat. Brain Res 554: 312-314.

Yehuda R, Fairman KR, Meyer JS (1989) Enhanced brain cell proliferation following early adrenalectomy in rats. J Neurochem 53: 241-248. 